\title{
Vessel Sealing Device in Parotid Gland Surgery: Clinical and Pathological Study
}

\author{
Isao Uemaetomari ${ }^{1}$, Tetsuro Wada ${ }^{1}$, Bungo Nishimura ${ }^{1}$, Shuho Tanaka ${ }^{1}$, Masahiro \\ Nakayama ${ }^{1}$, Kei Ashizawa ${ }^{1}$, Keiji Tabuchi ${ }^{1}$, Yuko Minami ${ }^{2}$ and Akira Hara ${ }^{1}$ \\ ${ }^{1}$ Department of Otolaryngology, Faculty of Medicine, University of Tsukuba, Tsukuba, Japan \\ ${ }^{2}$ Department of Pathology, Faculty of Medicine, University of Tsukuba, Tsukuba, Japan
}

Correspondence should be addressed to: Isao Uemaetomari; uemae@md.tsukuba.ac.jp

Received 8 November 2012; Accepted 6 December 2012; Published 28 May 2013

Academic Editor: Vassilios A. Lachanas

Copyright (c) 2013 Isao Uemaetomari, Tetsuro Wada, Bungo Nishimura, Shuho Tanaka, Masahiro Nakayama, Kei Ashizawa, Keiji Tabuchi, Yuko Minami and Akira Hara. Distributed under Creative Commons CC-BY 3.0

\begin{abstract}
Facial palsy, salivary leakage and postoperative bleeding are the main complications in parotid gland surgery. To find ways to reduce the occurrence of these complications, we compare traditional methods using the hand-tie ligation technique with a bipolar electrode knife against LigaSure ${ }^{\mathrm{TM}}$ Small Jaw, a newly developed vessel sealing device, in parotid gland operations.

Eighteen parotid gland tumour cases were retrospectively evaluated. All patients were treated in the University of Tsukuba Hospital, Ibaraki, Japan between January, 2011 and October, 2012. The patient groups were randomly allocated. Surgery was performed in eight cases with LigaSure ${ }^{\mathrm{TM}}$ Small Jaw, and ten consecutive cases were done with the conventional dissection technique. The clinical records and histopathological findings were reviewed for each group.

In this study we could not find any difference between the two groups in clinical issues. However, difference in histological damage was revealed at the cut edges of the connective tissue, nerve and salivary gland, i.e., less damage to the nerve was observed in the LigaSure ${ }^{\mathrm{TM}}$ Small Jaw group. These findings indicated that LigaSure ${ }^{\mathrm{TM}}$ Small Jaw was a safe and useful device for parotid gland surgery.
\end{abstract}

Keywords: Parotid gland, operation, LigaSure ${ }^{\mathrm{TM}}$ Small Jaw.

\section{Introduction}

The LigaSure ${ }^{\mathrm{TM}}$ vessel-sealing device (Covidien, Mansfield, MA, USA) is comparatively new equipment, featuring a computer-based, temperature-controlled bipolar electrocoagulation system. So far, LigaSure ${ }^{\mathrm{TM}}$ has been mainly applied to chest, gynecological, gastroenterological, and urological surgery (Levy and Emery, 2003;

Cite this Article as: Isao Uemaetomari, Tetsuro Wada, Bungo Nishimura, Shuho Tanaka, Masahiro Nakayama, Kei Ashizawa, Keiji Tabuchi, Yuko Minami and Akira Hara (2013), "Vessel Sealing Device in Parotid Gland Surgery: Clinical and Pathological Study," Advances in Cancer Research \& Treatment, Vol. 2013 (2013), Article ID 992721, DOI: 10.5171/2013. 992721 
Leonardo et al., 2005; Tsunezuka et al., 2010; Gehrig et al., 2011). LigaSure $^{\mathrm{TM}}$ can consistently, reliably and permanently seal off vessels and connective tissue. Thus, it is reported to save operation time by reducing sutures in thyroid surgery (Schiphorst et al., 2012). Although the conventional dissection technique using the hand-tie ligation technique and a bipolar electrode knife has been usual practice, some reports have described use of LigaSure Precise TM, an earlier model of LigaSure ${ }^{\mathrm{TM}}$ Small Jaw, in parotid gland surgery (Prokopakis et al., 2005; Colella et al., 2005; Colella and Giudice, 2006) Shortening of the operative time and decrease in risk of facial nerve damage were reported for using LigaSurePrecise ${ }^{\mathrm{TM}}$ (Prokopakis et al., 2005; Colella et al., 2005).The difference between LigaSurePrecise $^{\mathrm{TM}}$ and LigaSure ${ }^{\mathrm{TM}}$ Small Jaw, which debuted in 2007, is the addition of a cutter. The basic mechanism is considered to be the same, although it is said that performance, such as sealing time, is improved in the new model. LigaSure ${ }^{\mathrm{TM}}$ Small Jaw has not been reported as far as we could find.

\section{Materials and Methods}

Eighteen parotid gland tumor cases were retrospectively evaluated. All patients were treated in the University of Tsukuba Hospital, Ibaraki, Japan between January, 2011 and October, 2012. The patient groups were randomly allocated. The operation was performed in eight cases with LigaSure ${ }^{\mathrm{TM}}$ Small Jaw (Fig. 1), and ten consecutive cases were done with the conventional dissection technique.

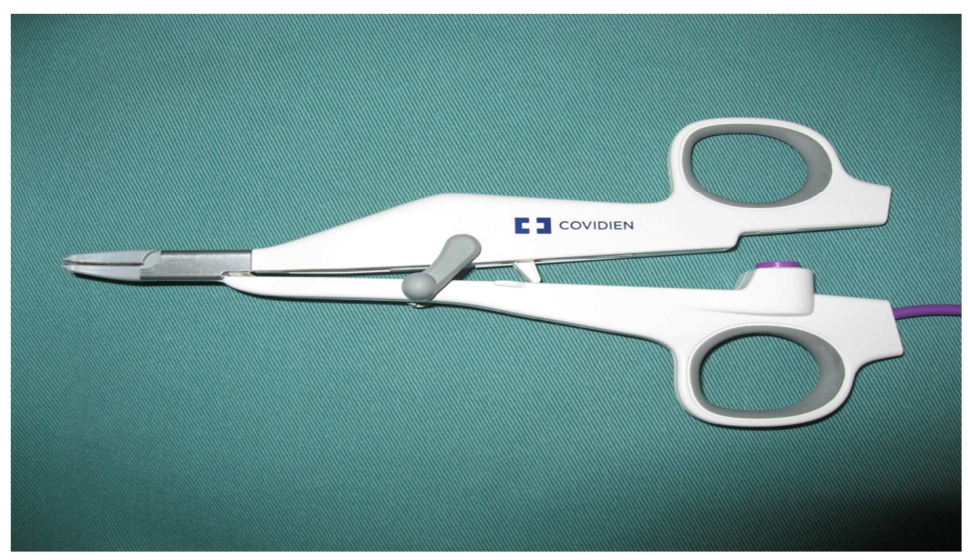

Figure1. LigaSure ${ }^{\mathrm{TM}}$ Small Jaw

The clinical records and histopathological findings were reviewed for the nine cases using LigaSure ${ }^{\mathrm{TM}}$ Small Jaw and ten cases using traditional methods with respect to complications, operative time, quantities of operative haemorrhage and histological evaluation of the excision stump.

\section{Results}

The average patient age in the parotidgland tumor cases using LigaSure ${ }^{\mathrm{TM}}$ Small Jaw was 54.5 years. Histologically, pleomorphic adenoma (including deep lobe tumour of the parotid gland) and Warthintumour were included; the mean tumour size was $34 \mathrm{~mm}$. Mean operative time, mean amount of bleeding and mean drain custody period were 140 minutes, $41 \mathrm{ml}$ and3.0 days, respectively. No patient developed complications except for a malignant case with facial paralysis, in which the facial nerve was intended to be sacrificed. On the other hand, the average age of the 10 patients that underwent traditional methods was 50.4 years. Histologically, nine cases of 
pleomorphic adenoma and one case of Warthintumour were included. Mean operative time, mean amount of bleeding and mean drain custody period were 165 minutes, $15.6 \mathrm{ml}$ and 3.2 days, respectively (Table 1). One case developed postoperative salivary leakage in this group.

The histological evaluation under hematoxylin and eosin staining of the excision stump of the salivary gland and connective tissue of the two groups revealed that in the LigaSure ${ }^{\mathrm{TM}}$ Small Jaw group damage to the tissue was limited to around $1 \mathrm{~mm}$ and there tended to be less thermal denaturation (Fig. 2A). In addition, in the one malignant tumour case in which a tumour was removed with the facial nerve, it was recognized that histological damage from the stump to the facial nerve was less than approximately $1 \mathrm{~mm}$ (Fig. 2B). On the other hand, in the traditional methods group the histological damage at the excision stump was slightly more severe than in the LigaSure $^{\mathrm{TM}}$ Small Jaw group, and the extension of the damage from the excision stump was over $1.5 \mathrm{~mm}$ (Fig. $3 \mathrm{~A}$ ). Moreover, in the LigaSure ${ }^{\mathrm{TM}}$ Small Jaw group, the excision stump of the salivary gland was shielded from all surroundings with degeneration (Fig. 2C).
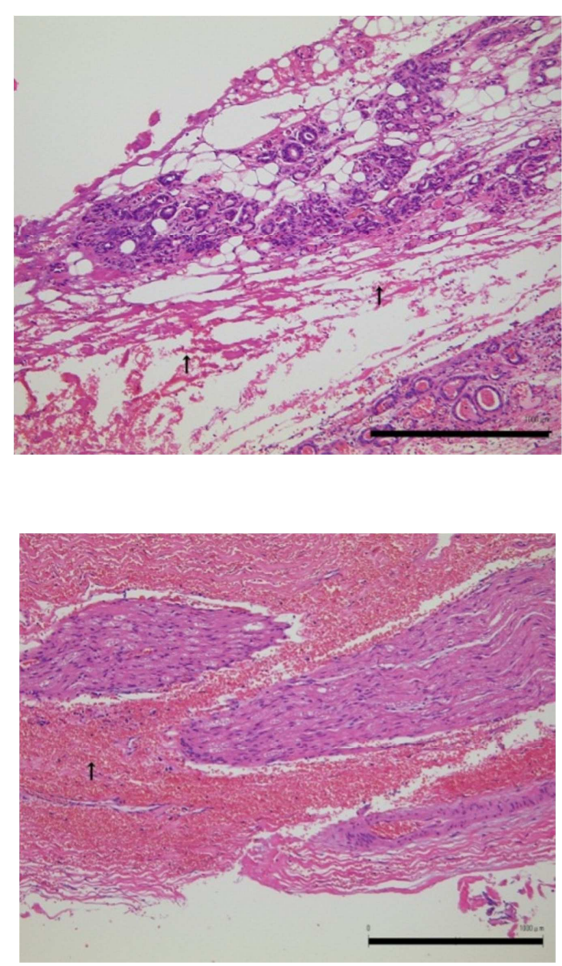

Isao Uemaetomari, Tetsuro Wada, Bungo Nishimura, Shuho Tanaka, Masahiro Nakayama, Kei Ashizawa, Keiji Tabuchi, Yuko Minami and Akira Hara (2013), Advances in Cancer Research \& Treatment, DOI: $10.5171 / 2013.992721$ 


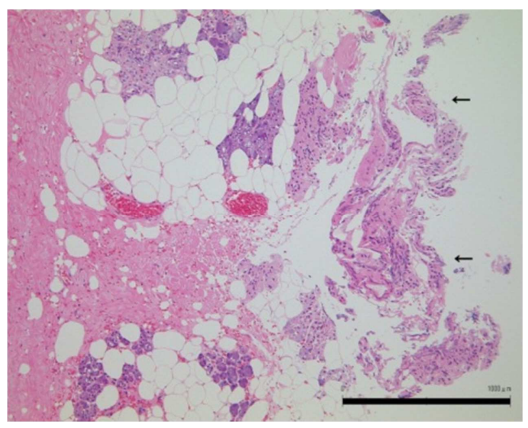

Figure 2 A, B, C. Histological Findings of the Surgical Stump of LigaSure ${ }^{\mathrm{TM}}$ Small Jaw. Damage to the Tissue was Limited to around $1 \mathrm{~mm}$ (Arrows) (A). Histological Damage from Stump to the Facial Nerve was Approximately less than 1mm (Arrows) (B). The Salivary Gland was Shielded against all Surroundings with Degeneration (Arrows) (C). HE, bar $=1000 \mu \mathrm{m}$.

Similarly, degeneration was observed around a suture thread in the traditional methods group, and the degeneration was particularly severe at the site of the inside side of the thread where the pressure of the ligature applied (Fig. 3B).
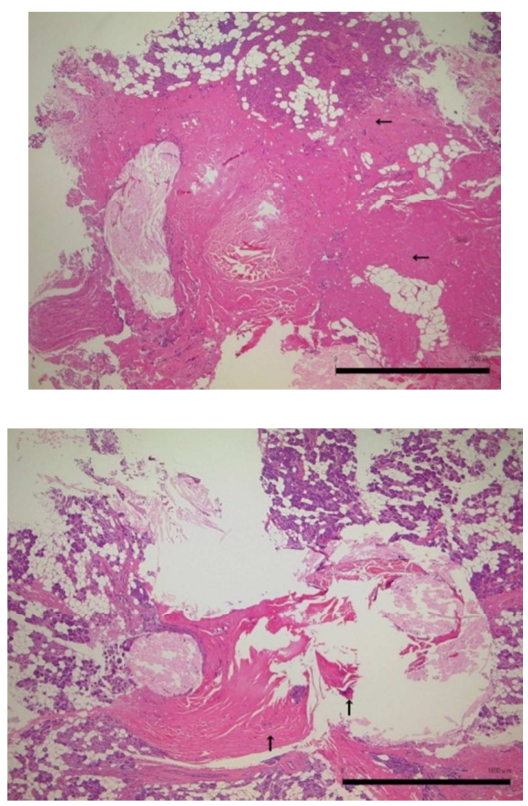

Figure 3 A, B. Histological Findings about the Surgical Stump in the Traditional Methods Group. Extension of Damage from the Excision Stump was over 1.5mm (Arrows) (A). Degeneration was Particularly Severe at the Inside of the Thread where the Pressure of the Ligature Applied (arrows) (B). HE, bar $=1000 \mu \mathrm{m}$.

\section{Discussion}

Recently, supersonic wave coagulation cutting devices and new energy devices such as LigaSure ${ }^{\mathrm{TM}}$ have been used for many operations. However, so far traditional methods like the hand ligation technique and the bipolar electrode knife have mainly been

Isao Uemaetomari, Tetsuro Wada, Bungo Nishimura, Shuho Tanaka, Masahiro Nakayama, Kei Ashizawa, Keiji Tabuchi, Yuko Minami and Akira Hara (2013), Advances in Cancer Research \& Treatment, DOI: $10.5171 / 2013.992721$ 
used in parotid gland surgery to avoid facial nerve damage. Therefore, the operation is lengthy, and there are risks such as postoperative bleeding and salivary fistulas when the ligations become loosened. Moreover, ligature left inside the body can pose a risk of postoperative infection. Also, the electrode knife used during parotid gland surgery is well known for its potential to cause nerve damage by heat and direct electric current. Moreover, the possibility of heat damage from the ultrasonic wave surgical knife has also been pointed out (Kim et al., 2008). LigaSure ${ }^{\mathrm{TM}}$ Small Jaw could be used instead of hand ligation, because it was reported that heat damage was comparatively slight (Seehofer et al., 2012).

LigaSure $^{\mathrm{TM}}$ Small Jaw is called a vessel sealing system. Collagen and elastin are denatured, and then the intravascular lumen is occluded; it fuses the vessel walls, and the blood stream is intercepted. First of all, LigaSure $^{\mathrm{TM}}$ Small Jaw senses the tissue at the point of the device, and the best pressure is applied; the main body of LigaSure ${ }^{\mathrm{TM}}$ measures the tissue impedance, and an appropriate energy setting is selected. In addition, feedback control and high frequency energy is supplied, and the output is adjusted automatically. The output also automatically stops when the seal is completed, and the tissue is cut with the attached surgical knife by the surgeon's hand. Generally, heat damage to tissue is believed to spread wide if the voltage is high, like with the electrode knife, and the current is low. Inversely, it is supposed that protein will fuse and integrate in a short time and scorching is suppressed because of the high current and the decreased voltage in LigaSure ${ }^{\mathrm{TM}}$ Small Jaw. A lot of experiences of the efficacy of LigaSure $^{\mathrm{TM}}$ have been reported in chest, gynecological, gastroenterological, urological surgeryand so on (Levy and Emery, 2003; Leonardo et al, 2005; Tsunezuka et al., 2010; Gehrig et al., 2011).Recently, the number of reports about using ultrasonic wave coagulation cutting devices and an advanced bipolar device such as LigaSure ${ }^{\mathrm{TM}}$ has increased for thyroid surgery in the head and neck region (Prokopakis et al., 2010). As for LigaSure $^{\mathrm{TM}}$ Small Jaw used in parotid gland surgery, no report has been made until now as far as we could find. We have clinically and histologically examined the effect of using LigaSure $^{\mathrm{TM}}$ Small Jaw in parotid gland surgery.

As a comparison with parotid gland surgery using LigaSure ${ }^{\mathrm{TM}}$ Small Jaw, ten consecutive cases of parotid benign tumour surgery in our department using the hand ligation technique were examined. The average operation time was 165 minutes, the average amount of bleeding was $15.6 \mathrm{ml}$, and the average drain custody period was 3.2 days with this conventional method. On the other hand, the average operation time was 140 minutes, the average amount of bleeding was $41 \mathrm{ml}$, and the average drain custody period was 3.0 days using LigaSure ${ }^{\mathrm{TM}}$ Small Jaw. Although the cases were limited in number, there was no significant difference between the two groups. However, shortened operation time using LigaSurePrecise ${ }^{\mathrm{TM}}$ compared with the traditional methods has been reported. It was considered that because bigger and deeper lobes of parotid gland tumour were included in the LigaSure $^{\mathrm{TM}}$ Small Jaw group, therefore excessive blood loss was experienced in these cases compared with the traditional method cases. On the other hand, less bleeding has been reported when using LigaSurePrecise $^{\mathrm{TM}}$ than the traditional methods, especially in patient who are at risk of haemorrhage (Prokopakis et al., 2005; Colella et al., 2005). The United States FDA (US Food and Drug Administration) authorizes LigaSure ${ }^{\mathrm{TM}}$ for cutting blood vessels and lymphatic vessels up to $7 \mathrm{~mm}$ in diameter, and the resisting pressure is reported to be three times or more than usual arterial pressure (Kennedy et al., 1998; Heniford et al., 2001; Harold et al., 2003; Dubuc-Lissoir, 2003).Therefore, it was suggested that less bleeding was accomplished. Secure sealing of the salivary duct was also expected in the same way. We had one case of salivary fistula among the ten traditional method cases. Therefore, it was 
thought that a further investigation would be required concerning salivary fistulain parotid gland surgery using LigaSure ${ }^{\mathrm{TM}}$ Small Jaw.

It was mentioned in previous reports (Kennedy et al., 1998; Heniford et al., 200; Harold et al., 2003; Dubuc-Lissoir, 2003) on LigaSure $^{\mathrm{TM}}$ use that heat was transmitted from the device to the surrounding structures to the extent of about $1.5-3.3 \mathrm{~mm}$. Cell denaturation was limited to about $1 \mathrm{~mm}$ of the surrounding tissues in our investigation of damage by LigaSure ${ }^{\mathrm{TM}}$ Small Jaw to the cutting stump. Preservation of the facial nerve was thought to be possible, if there was a distance of $1 \mathrm{~mm}$ or more between the cutting edge and the facial nerve. It was reported that facial palsy was also a rare complication after parotid gland surgery using LigaSurePrecise ${ }^{\mathrm{TM}}$ (Prokopakis et al., 2005; Colella et al., 2005).

Previous reports said the operation time with LigaSurePrecise ${ }^{\mathrm{TM}}$ was shortened. This was supposed to be due to the omission of hand ligation time. Similar to the previous report, in our cases operation time with LigaSure ${ }^{\mathrm{TM}}$ had a tendency to be shorter, although the difference was not significant because of the limited number of cases.

Although there were no clinical or histology investigations about its use in parotid gland surgery so far, LigaSure ${ }^{\mathrm{TM}}$ Small Jaw was thought to be as a useful device as LigaSurePrecise ${ }^{\mathrm{TM}}$ was reported to be in the past. Regarding complications of parotid gland surgery using LigaSure ${ }^{\mathrm{TM}}$ Small Jaw and damage to near organs, coexisting complications such as facial palsy, salivary fistulas and postoperative bleedings were not identified in our study, but the number of cases was limited. According to past reports on LigaSurePrecise ${ }^{\mathrm{TM}}$ and our study, LigaSure $^{\mathrm{TM}}$ Small Jaw has the potential to reduce complications and shorten operation time. Further research is necessary to investigate the cost-effectiveness of LigaSure $^{\mathrm{TM}}$ Small Jaw.

\section{Conclusion}

In this study, complications of parotid gland surgery using LigaSure ${ }^{\mathrm{TM}}$ Small Jaw are not identified, though the number of cases is limited. Moreover, histological examination reveals less damage to the nerve at the cut edge of the connective tissue, nerve and salivary gland in the LigaSure ${ }^{\mathrm{TM}}$ Small Jaw group. Our findings indicate that LigaSure ${ }^{\mathrm{TM}}$ Small Jaw is a safe and useful device for parotid gland surgery.

\section{References}

Colella, G. \& Giudice, A. (2006). "LigaSure Device in Parotid Gland Surgery," Otolaryngol Head Neck Surg, 135, 172-173.

Colella, G., Giudice, A., Vicidomini, A. \& Sperlongano, P. (2005). "Usefulness of the LigaSure Vessel Sealing System during Superficial Lobectomy of the Parotid Gland," Arch Otolaryngol Head Neck Surg, 131, 413416.

Dubuc-Lissoir, J. (2003). "Use of a New Energy-Based Vessel Ligation Device during Laparoscopic Gynecologic Oncologic Surgery," SurgEndosc, 17, 466-468.

Gehrig, T., Müller-Stich, B. P., Kenngott, H., Fischer, L., Mehrabi, A., Büchler, M. W. \& Gutt, C. N. (2011). "LigaSure versus Conventional Dissection Technique in Pancreatoduodenectomy: A Pilot Study," Am J Surg, 201, 166-170.

Harold, K. L., Pollinger, H., Matthews, B. D., Kercher, K. W., Sing, R. F. \& Heniford, B. T. (2003). "Comparison of Ultrasonic Energy, Bipolar Thermal Energy, and Vascular Clips for the Hemostasis of Small-, Medium-, and Large-Sized Arteries," SurgEndosc, 17, 12281230.

Heniford, B. T., Matthews, B. D., Sing, R. F., Backus, C., Pratt, B. \& Greene, F. L. (2001). "Initial Results with an Electrothermal 
Bipolar Vessel Sealer," SurgEndosc, 15, 799801.

Kennedy, J. S., Stranahan, P. L., Taylor, K. D. \& Chandler, J. G. (1998). "High-Burst-Strength, Feedback-Controlled Bipolar Vessel Sealing," SurgEndosc, 12, 876-878.

Kim, F. J., Chammas, M. F. Jr., Gewehr, E., Morihisa, M., Caldas, F., Hayacibara, E., Baptistussi, M., Meyer, F. \& Martins, A. C. (2008). "Temperature Safety Profile of Laparoscopic Devices: Harmonic ACE (ACE), Ligasure V (LV), and Plasma Trisector (PT)," SurgEndosc, 22, 1464-1469.

Leonardo, C., Guaglianone, S., De Carli, P., Pompeo, V., Forastiere, E. \& Gallucci, M. J. (2005). "Laparoscopic Nephrectomy Using Ligasure System: Preliminary Experience," Endourol, 19, 976-978.

Levy, B. \& Emery, L. (2003). "Randomized Trial of Suture versus Electrosurgical Bipolar Vessel Sealing in Vaginal Hysterectomy," Obstet Gynecol, 102, 147-151.

Prokopakis, E. P., Lachanas, V. A., Helidonis, E. S. \& Velegrakis, G. A. (2005). "The Use of the Ligasure Vessel Sealing System in Parotid Gland Surgery," Otolaryngol Head Neck Surg, $133,725-728$.

Prokopakis, E. P., Lachanas, V. A., Vardouniotis, A. S. \& Velegrakis, G. A. (2010). "The Use of the Ligasure Vessel Sealing System in Head and Neck Surgery: A Report on Six Years of Experience and a Review of the Literature," B-ENT, 6, 19-25.

Schiphorst, A. H. W., Twigt, B. A., Elias, S. G. \& van Dalen, T. (2012). "Randomized Clinical Trial of LigaSure versus Conventional Suture Ligation in Thyroid Surgery," Head Neck Oncol, 18, 4, 2.

Seehofer, D., Mogl, M., Boas-Knoop, S., Unger, J., Schirmeier, A., Chopra, S. \& Eurich, D. (2012). "Safety and Efficacy of New Integrated Bipolar and Ultrasonic Scissors Compared to Conventional Laparoscopic 5- mm Sealing and Cutting Instruments," SurgEndosc, 26, 2541-2549.

Tsunezuka, Y., Waseda, R.- I. \& Yachi, T. (2010). "Electrothermal Bipolar Vessel Sealing Device LigaSureV for Pulmonary Artery Ligation--Burst Pressure and Clinical Experiences in Complete Video-Assisted Thoracoscopic Major Lung Resection for Lung Cancer," ThoracSurg, 11, 229-233.

Isao Uemaetomari, Tetsuro Wada, Bungo Nishimura, Shuho Tanaka, Masahiro Nakayama, Kei Ashizawa, Keiji Tabuchi, Yuko Minami and Akira Hara (2013), Advances in Cancer Research \& Treatment, DOI: $10.5171 / 2013.992721$ 